\title{
BRAIN DEVELOPMENT OF SCHOOL-AGE CHILDREN ATTENDING TO SCHOOLS WITH HIGH, MEDIUM AND LOW ACHIEVEMENT IN THE SIMCE TEST
}

\author{
D.M. Ivanovic ${ }^{1}$, C.V. Ibaceta ${ }^{1}$, Y.Z. Orellana ${ }^{1}$, V.C. Arancibia ${ }^{2}$, A.M.O. Neira ${ }^{1}$, G.I. Morales ${ }^{3}$, A.F. \\ Almagià ${ }^{4}$, P.A. Lizana ${ }^{4}$, R.A. Burrows ${ }^{1}$ \\ ${ }^{1}$ Institute of Nutrition and Food Technology (INTA), University of Chile, ${ }^{2}$ Faculty of Social Sciencies, School \\ of Psychology, PENTA UC, Pontifical Catholic University of Chile, ${ }^{3}$ Faculty of Medicine, University of \\ Chile, Santiago, ${ }^{4}$ Institute of Biology, Laboratory of Physical Anthropology and Human Anatomy, Pontifical \\ Catholic University of Valparaiso, Valparaiso, Chile
}

Background and aims: Our previous studies reveal that head circumference, the anthropometric index of both nutritional background and brain development, is the most relevant physical index associated with scholastic achievement and intellectual ability in Chilean school-age children. The aim of this study was to determine the brain development of school-age children attending to schools with high, medium and low achievement in the SIMCE test.

Methods: A representative sample of 26 schools classified with high, medium and low achievement in the SIMCE tests was randomly chosen in the Metropolitan Region of Chile. The sample consisted of 901 schoolage children who in 2009 gave the SIMCE (Education Quality System Measurement from the Ministry of Education) tests and who completed the subjects' consent according to the Declaration of Helsinki. Brain development was measured through the head circumference (HC) expressed as Z-HC and categorised as follows: $<-2 \mathrm{SD},-2 \mathrm{SD}$ to $<0 \mathrm{SD}, 0 \mathrm{SD}$ to $2 \mathrm{SD}$ and $>2 \mathrm{SD}$. Data were processed using the SAS package.

Results: Children with $\mathrm{HC}<-2 \mathrm{SD}$ and $>2 \mathrm{SD}$ mainly attended to schools with low and high SIMCE results (60\% and $56.8 \%$, respectively) $\left(\mathrm{X}^{2}=40.539 ; 10 \mathrm{df} ; \mathrm{P}<0.001\right)$. In schools with high and medium SIMCE results, $66.8 \%$ and $56.2 \%$ of children had $\mathrm{HC}>0 \mathrm{SD}$ and in schools with low SIMCE results, $51 \%$ had HC values $<0 \mathrm{SD}\left(\mathrm{X}^{2}=19.566 ; 2 \mathrm{df} ; \mathrm{P}<0.001\right)$.

Conclusions: As we said previously, $\mathrm{HC}$ values immediately under the mean are associated with an increased incidence of lower scholastic achievement in Chilean school population.

Grant FONDECYT 1100431. 